ISSUES IN MEDICINE

\title{
Handmaidens and pioneers: Three female anaesthetists and their contribution to anaesthesia in South Africa
}

\author{
C Gordon, ${ }^{1} \mathrm{PhD} ;$ P C Gordon, ${ }^{2} \mathrm{MB}$ BCh, FFA (SA) \\ ${ }^{1}$ School of Language, Literature and Media, Faculty of Humanities, University of the Witwatersrand, Johannesburg, South Africa \\ ${ }^{2}$ Department of Anaesthesia, University of Cape Town; and Nagin Parbhoo History of Anaesthesia Museum, Cape Town, South Africa
}

Corresponding author: P C Gordon (peter.gordon@uct.ac.za)

The period during and after World War II saw enormous changes in the practice and status of anaesthesia, as well as in female participation. This article offers an account of three South African (SA) women who trained in anaesthetics before and during the War and participated in these changes. By the mid-1960s, they presided over the three independent anaesthetic departments at Johannesburg's three main teaching hospitals, teaching generations of junior doctors. The first woman to register as a specialist anaesthetist in SA, Miriam (Mollie) Barlow, broke the glass ceiling in her own career by lobbying for the professional rights of medical women, although working within the constraints of the medical and political establishment. She also contributed to important SA research on malignant hyperthermia. Hilde Ginsberg collaborated with Barlow in the 1950s, reducing intraoperative and perioperative mortality at Coronation Hospital, and fought for key interventions in anaesthetic practice and policy through the South African Society of Anaesthetists (SASA), becoming its most long-serving and honoured female member. Kathleen Barbara Vetten's exemplary career in academic medicine, including pioneering animal research (developing anaesthetic techniques for open-heart surgery in dogs and protocols for liver transplantation in primates) and a successful operation to separate craniopagus twins, shows both the achievement of and limits to female achievement at the end of this period. This article also offers a short account of factors that hindered black women from entering anaesthesia training, contributing to this history before the 1990s.

S Afr Med J 2020;110(11):1088-1092. https://doi.org/10.7196/SAMJ.2020.v110i11.14588

Anaesthesia was born a slave; and she has ever remained the faithful handmaid of her master surgery (F W Hewitt ${ }^{[1]}$

... it is only in the past two or three years that surgeons have belatedly and grudgingly recognised the inestimable value of the work of the anaesthetist ... From being the handmaiden of surgery, anaesthesia has advanced to the status of complete equality (G Sacks) ${ }^{[2]}$

The surgeons considered anaesthetists their 'handmaidens'... (H Ginsberg) $)^{[3]}$

When Cape Town surgeon George Sacks, paying obituary tribute to anaesthetist Royden Muir in 1948, offered to reverse Sir Frederick Hewitt's observation that the anaesthetist is the natural helpmeet, if not the slave, of surgery, ${ }^{[1]}$ he was obliged to acknowledge that the colleague who inspired such respect for anaesthesia had died frustrated and disillusioned with its status in South Africa (SA). ${ }^{[2]}$ Hilde Ginsberg recalled her experience as a resident anaesthetist in the Johannesburg hospital system in 1938: 'The surgeons considered anaesthetists their "handmaidens" ... when they booked their list they indicated the type of anaesthetic they required, e.g. spinal or general. Sometimes even gas and oxygen.' ${ }^{[3]}$

Early anaesthetists were effectively subcontracted labour, their value being determined by the surgeon, on whose patients they worked, sometimes for as little as $5 \%$ of the surgeon's fee, ${ }^{[3]}$ or rated at nothing when they tried to collect from patients (Fig. 1). Anaesthetists in SA public hospitals were employed as honorary anaesthetists, brought in by the surgeons with whom they worked in private practice. The demand for anaesthesia in the country's vast, sparsely populated interior served initially to diminish rather than raise its value. In 1927, the medical establishment was forced to acknowledge that while it was 'detrimental to the honour and interests of the medical profession to employ an unregistered person as a paid anaesthetist at an operation ..., it was sometimes necessary to lower the bar. 'Any practitioner [could] legally employ anyone whomsoever as an anaesthetist, he shouldering the whole responsibility. ${ }^{\text {[4] }}$ In cases of intraoperative death, however, legal responsibility fell heavily on anaesthetic practitioners, who were 'frequently often called upon to anaesthetize moribund cases with the practical certainty of having to face a public inquest. ${ }^{[5]}$

The factors that made the SA anaesthetist's work financially, legally and reputationally precarious, created opportunities for women. Lower remuneration and status meant that anaesthetic house jobs were less competitive and more likely to be offered to women. The notion of the anaesthetist as ancillary to the surgeon made anaesthetics appear a 'natural' choice for the female specialist (joining gynaecology and obstetrics), and an anaesthetic career was perceived as being compatible with family responsibilities. After World War II, which created more space for female participation, both the practice and status of anaesthesia were transformed. As anaesthesia struggled to throw off the shackles of its role as surgery's handmaiden, it was helped by three women: Miriam (Mollie) Brereton Barlow, Hilde Ginsberg and Kathleen Barbara Vetten.

\section{Backgrounds}

Many women who entered medicine, such as Barlow and Ginsberg, came from families connected to the medical profession. There were several generations of male doctors in Barlow's family. Her father, Col. Cresswell, a journalist, farmer and member of Parliament, invested heavily in the education of his 4 daughters, of whom 3 became doctors. ${ }^{[6]}$ Ginsberg, born of German Jewish émigrés, pursued a career in medicine following a visit to her medical student cousin in 


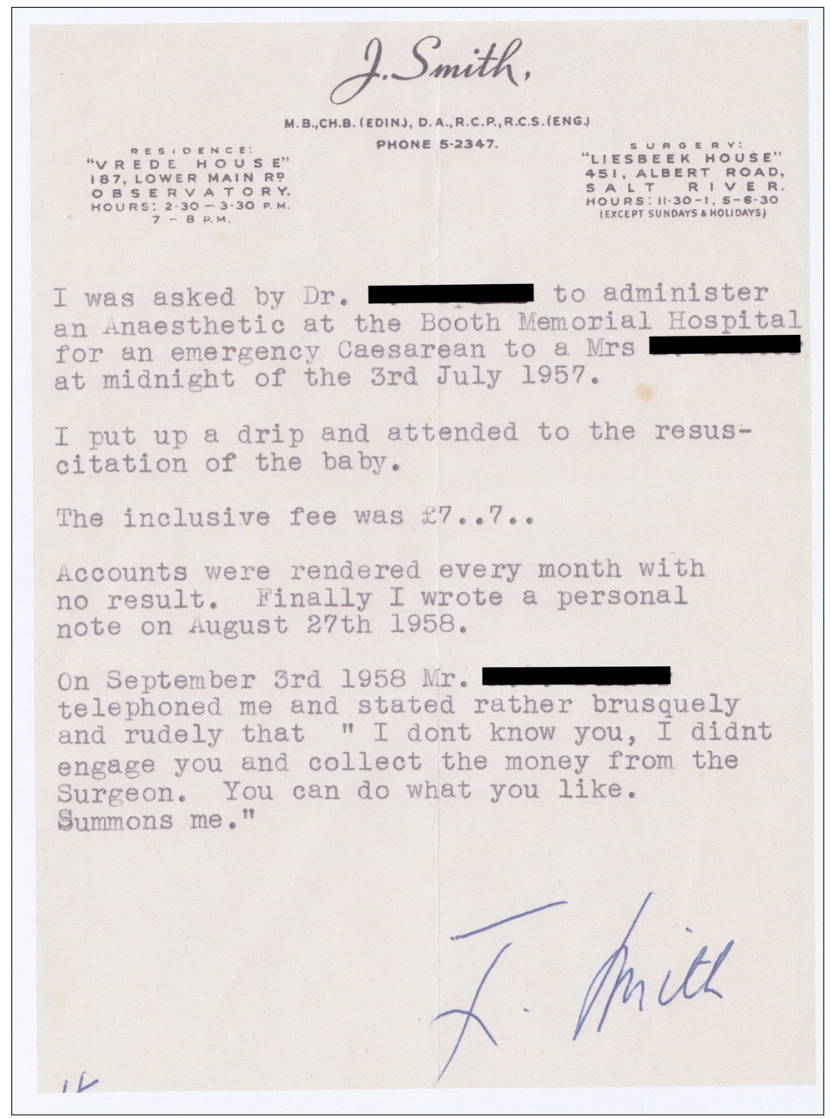

Fig. 1. Statement from anaesthetist, documenting anaesthetic bill unpaid for longer than a year, and husband of patient's explicit refusal to recognise the fee.

Germany in $1929 .{ }^{[7]}$ Vetten was born into a non-medical professional family, the daughter of a magistrate, but encountered science through her mother's keen interest in palaeontology, reflected in the paper on early human Boskop Man remains that Vetten published in her second year of medicine. ${ }^{[8]}$

For all three, a key aspect of their background was their whiteness. Before 1941, clinical training in SA was closed to black students, and while notable black doctors entered the profession through overseas training, with backing from family and institutions such as Christian missions, few women were afforded this opportunity. ${ }^{[9]}$ When the University of the Witwatersrand (Wits) provisionally opened its doors to black students in 1941, and the University of Cape Town (UCT) in 1943, medical training became more accessible and women began qualifying. ${ }^{[10]}$ Female general practitioners played an important role in communities. ${ }^{[10]}$ However, there were significant barriers to black women specialising in medicine. Anaesthesia lacked the status of surgery and the anaesthetist was required to work with (or, less generously, under) a surgeon, which created further professional barriers for black doctors under apartheid.

As anaesthesia developed into a highly technical and scientific specialist discipline, poor scientific and mathematical education was a significant stumbling block for black medical trainees. Hendrik Verwoerd introduced the 1953 Bantu Education Act, designed to fit black students for the unskilled labour market: 'What is the use of teaching the Bantu child mathematics ...?? ? $^{[1]}$ Thirty years later, Prof. Phillip Tobias noted the catastrophic effects of apartheid policy on medical training, which had put the country overall ' 30 years behind a point where it could and should have been. $^{\text {, }}{ }^{12]}$
White women experiencing a segregated teaching environment that excluded them from specific teaching spaces, such as anatomy halls, were still able to pass through the system, and might even have experienced the separation as beneficial. ${ }^{[13]}$ Racial segregation, however, served only to limit and exclude black doctors. The message was clear when Wilson Conco, who graduated top of his class from Wits in 1947, ${ }^{[14]}$ was demoted from his position as demonstrator in the histology laboratory to demonstrator to 'non-European' students only, following pressure from media and government. ${ }^{[15]}$ The first black woman to specialise in anaesthesia in SA, Elizabeth (Lizzy) Mthombeni, qualified MMed from MEDUNSA in 1992, nearly 60 years after Barlow. The first black SA woman to specialise through the College of Anaesthetists of SA, Thobeka Mabusela, obtained her Fellowship in 2002.

\section{Breaking the glass ceilling}

Barlow was in many respects a pioneer. A notably privileged position gave her a head start and, once embarked on her career, she largely kept her place at the vanguard, though as, in Liz Walker's phrase, a 'conservative pioneer. ${ }^{[}{ }^{16]}$ Choosing medicine over mathematics, she qualified MB ChB at UCT in 1931, the youngest in her class at the age of 21. ${ }^{[6]}$ Although 1933 was the height of the Great Depression, she was able to travel to the UK to receive training in anaesthesia at the Warrington General Hospital. Returning in 1934, she became the first female to register as a specialist anaesthetist in SA, ${ }^{[17]} 1$ of only 6 practising in Johannesburg. ${ }^{[6]}$ She was appointed to the joint staff of Wits and Johannesburg General Hospital in an honorary capacity in 1936, ${ }^{[18]}$ working for 9 years and raising two children. ${ }^{[6]}$ In 1946 she took a full-time position at Coronation Hospital, was promoted to senior anaesthetist in $1950,{ }^{[18]}$ and became the first female head of a Wits medical department. ${ }^{[6]}$

Barlow was prominent, often pre-eminent, within professional bodies during a period when anaesthesia in SA made significant advances. She was a founding member of the SA Society of Anaesthetists (SASA) (1943), became the first female office bearer (secretary treasurer in 1946/1947), was elected the Society's first female president (1948) ${ }^{[3]}$ and was a founder member of the College of Physicians and Surgeons of SA (1954). ${ }^{[6]}$ Throughout her career, she was an active and diligent member of the Medical Association of SA (MASA) and was elected an honorary member in 1970. ${ }^{[17]}$ Barlow leveraged her professional status and family connections to lobby successfully for the professional advancement of women in medicine in the 1950s, when she worked with other medical women to raise the retirement age for female doctors to that of their male counterparts, forming SA's first Society for Medical Women (SASMW), serving as its first president, and fighting for 13 years to remove the bar to married women working in the state sector, which was applied in a highly discretionary manner after World War II. ${ }^{[13,16]}$

It is worth noting that the SASMW was formed (albeit reluctantly) on an instruction from MASA to 'establish a mandate amongst the Lady Medical Officers in full-time service and approach Dr Hugo the Provincial Administration direct so that you may solve the matter [of retirement age and pensions] amongst yourselves. ${ }^{[13]}$ This correspondence set the tone for how the Society would operate, particularly in its earlier years: an active executive using their networks and professional status to directly petition government, effective within a narrow, top-down remit, but limiting the voice of ordinary members. ${ }^{[13,16]}$ Under Barlow's leadership, the SASMW chose professional affiliation (with MASA) over broader (political and labour) affiliation with women's movements. ${ }^{[13]}$ MASA, perceived as aligned with the nationalist government, alienated large sections 
of the medical community, particularly after 1977, when it stood by the doctors under whose watch the activist Steve Biko had died, prompting resignations and a breakaway formation, and obliging MASA to resign its membership of the World Medical Association. ${ }^{[19]}$

\section{Collective action}

While Barlow's contributions through the SASMW have been well documented, ${ }^{[13,18]}$ perhaps as important are the contributions she made through SASA, often working with SASA's co-founder, Hilde Ginsberg. The two were colleagues at Coronation Hospital from 1949 to 1953, until Ginsberg was transferred to Baragwanath Hospital, ${ }^{[18]}$ where she would become a leading figure as Barlow at Coronation Hospital. Their collaboration led to a dramatic decrease in on-table deaths and postoperative mortality, which were attributed to improved training of junior staff and personal supervision of trainees. ${ }^{[20]}$ At the Society's annual general meeting (AGM) in 1955, Barlow, seconded by Ginsberg, proposed that the SA Medical and Dental Council be approached to institute compulsory teaching in anaesthetics for interns. Following discussion, the secretary was instructed to write to the Medical Council, requesting that 'every intern do at least one month of full-time compulsory training in anaesthetics .... This would do much to improve the standard of anaesthesia outside of academic hospitals and reduce perioperative mortality. In 1959, the Medical Council finally passed a rule requiring all interns to produce proof of having administered 50 anaesthetics under supervision during their intern year, which SASA's then president described as 'a great step forward in improving the standard of anaesthesia throughout the country. ${ }^{\text {[21] }}$

Ginsberg and Barlow also fought against the unfair treatment of anaesthetists at inquests into death on the operation table. At the 1960 SASA AGM, a motion recommending that 'Section 86 of the Inquest Act be abolished and that steps be taken to reduce the incidence of deaths related to anaesthesia by better training of practitioners and by improvement of facilities where anaesthetics are administered, and the training of nurses in the care of the unconscious patient should be vigorously pursued, was proposed by Ginsberg, seconded by Barlow and approved unanimously. ${ }^{[21]}$

Ginsberg and Barlow also fought to raise anaesthetic standards and to keep anaesthesia in the hands of the medical profession. When, in 1967, SASA was presented with a plan to train anaesthetic nurses in Durban, following the route taken in the USA and Europe, Ginsberg seconded a motion to oppose the training of persons other than medical practitioners and dentists in administration of anaesthetics, and Barlow seconded a rival proposal to introduce a diploma in anaesthetics for 'medical men' who did not want to specialise. ${ }^{[21]}$ The Colleges of Medicine of SA instituted the Diploma in Anaesthetics in 1974. ${ }^{[22]}$

During the Society's first 50 years, it would elect only two female presidents (Ginsberg and Barlow) (Fig. 2) and only two more in the following 25 years. ${ }^{[23]}$ In this rather sparse history of female leadership, Ginsberg would be called to serve three terms as SASA's president across three decades: in 1953/1954; 1961/1962; and 1971/1972. ${ }^{[3]}$

Barlow and Ginsberg worked together effectively as colleagues, researchers and SASA members during the 1940s, 1950s and 1960s, perhaps despite differences that later made themselves more apparent. While Barlow used her contacts in the apartheid administration to achieve specific gains for white women in the medical professions, without challenging larger structures, and kept SASMW in line with MASA (and thus with the National administration), Ginsberg was a member of the Black Sash. ${ }^{[7]}$ Her husband and colleague, Sam Wayburne, who ran paediatrics at Baragwanath Hospital, is reported to have leaked figures on black infant malnutrition in Soweto to the anti-apartheid press. ${ }^{[24]}$ Ginsberg's Wits alumnus obituary suggests that her

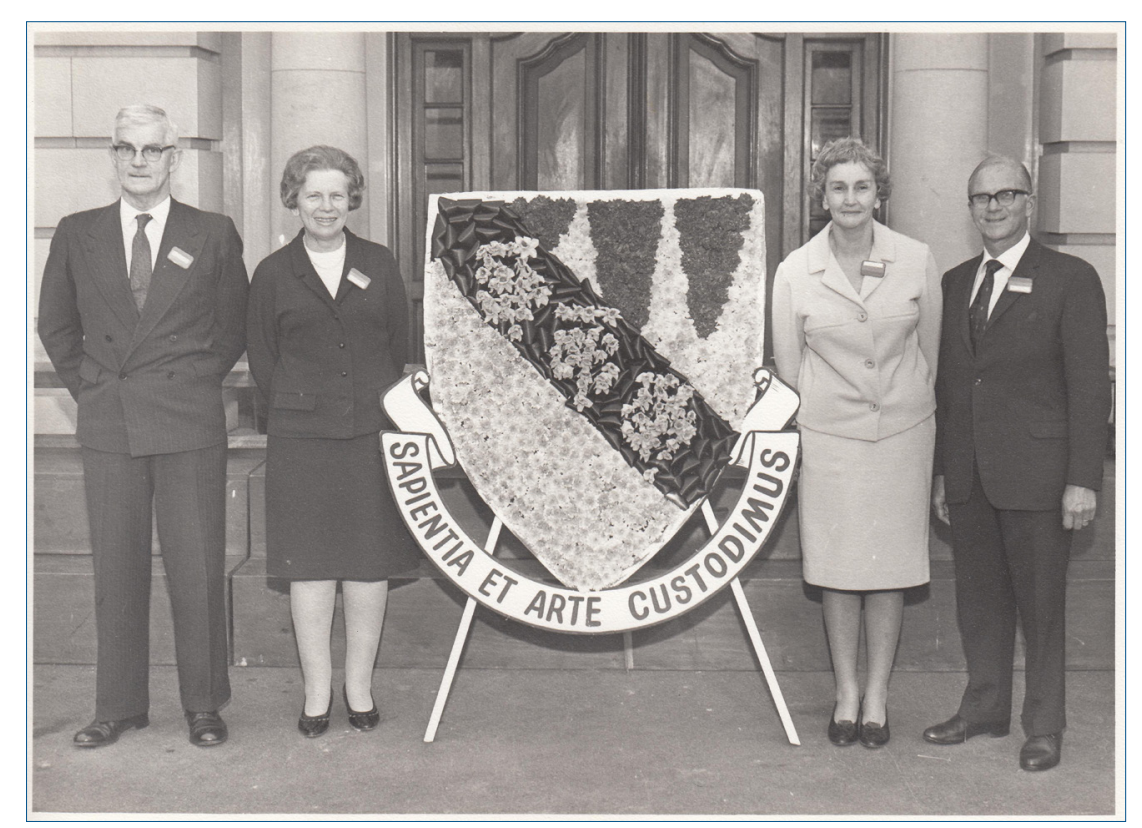

Fig. 2. Hilde Ginsberg (left) and Mollie Barlow (right), flanking the South African Society of Anaesthetists crest at the 25th Anniversary Congress, 1969. desire to campaign grew from her direct experience of antisemitism and prejudice against women ${ }^{[7]}$ It is interesting to contrast this with a formative experience of prejudice and empathy described by Barlow. In her short medical biography, she describes her close relationship with her highly intelligent brother, who, despite suffering cerebral palsy caused by a forceps delivery, became a lawyer and state counsel. 'In standing up for him when other children called him mad', she wrote, 'I learned to fight and to answer people back. This facility has helped greatly in my career. ${ }^{[6]}$

\section{The frustrated surgeon}

Barlow had embarked on a specialist path in anaesthesia on the recommendation of her future husband, who suggested that anaesthetics would 'fit in with married life. ${ }^{[6]}$ Ginsberg took what she was given after her internship: '... I wanted to stay on at the hospital as I was getting married. There were only 3 Senior House-jobs ENT, gynaecology and anaesthetics at the Johannesburg Hospital at that time and I got anaesthetics. ${ }^{[3]}$ Unlike Barlow and Ginsberg, who entered anaesthesia owing to availability and convenience, and who took on public and private work as it became available, with marriage and family a deciding factor in their careers, Barbara Vetten pursued a career in academic medicine and had specific specialist ambitions.

Vetten graduated MB BCh (Rand) in 1940. ${ }^{[18]}$ After completing rotations as a resident medical officer (RMO) in medicine 
and obstetrics and gynaecology, she applied for an RMO post in surgery and was accepted with the encouragement, '... if you don't do well we will never take on another woman again'. After completing two 6-month blocks in surgery, she applied to enter the academic programme but the professor of surgery bluntly informed her: 'I will not accept any woman for this exam. Surgery is not for women.' Blocked from surgery, Vetten chose the thing that would allow her 'to see it and to watch other people do it', and joined the Wits Department of Anaesthesia as a resident anaesthetist at Johannesburg Hospital in July 1942. ${ }^{[25]}$

At this point, Vetten had already published her second scientific paper, describing the mechanisms of athletic injuries. ${ }^{[26]}$ She delivered three sons and obtained the Wits DA (SA's first specialist anaesthetic qualification) ${ }^{[16]}$ in the first year of its existence before her next published paper in 1950. The paper compared the clinical use in humans of two new muscle relaxants, decamethonium iodide and curare, at a time when neostigmine was not yet used as a reversal agent. ${ }^{[27]}$ Two years later, she published an article on safety regarding the use of muscle relaxants, recommending gallamine. ${ }^{[28]}$

In 1953, Vetten became a key member of the Wits Cardiac Surgical Research Unit that, supported by the Nuffield Foundation, was performing preliminary research in animals as a forerunner to the establishment of an open-heart surgery unit in Johannesburg. In their early work, the group focused on developing a 'more precise' method than previously described for producing mitral incompetence in dogs, with survival. In this initial study, 6 of 12 dogs survived $>10$ days. ${ }^{[29]}$ Follow-up research investigated the haemodynamics of surgically induced mitral incompetence in dogs, with the objective of developing techniques for reconstructive surgery in mitral incompetence. ${ }^{[30,31]}$ The group also investigated methods to maintain an effective circulation in dogs after cardiac arrest during surgery, ${ }^{[32]}$ and artificial maintenance of circulation by both cross-perfusion between two living organisms and an artificial heart-lung pump. ${ }^{[33]}$ After testing various anaesthetic drugs and muscle relaxants in 150 dogs, and in the absence of anaesthetic literature on experimental cardiac surgery in dogs, she published a method to optimise the techniques and agents used to anaesthetise dogs undergoing experimental thoracic surgery. ${ }^{[34]}$

Vetten became the lead anaesthetist when the Johannesburg Hospital began performing open-heart surgery, and in 1965 reported on problems relating to anaesthesia for such surgery, using cardiopulmonary bypass in 240 cases. $^{[35]}$ In 1966 , she became the lead anaesthetist in the Johannesburg Hospital's new renal transplant programme. In an article describing their preliminary experience in 25 renal transplant procedures using living and cadaver donors, Vetten wrote, 'medical science was on the threshold of a new frontier, that is, the substitution of healthy organs for ones which are diseased and functionally inadequate for the maintenance of life. ${ }^{[36]}$ Demonstrating her versatility, Vetten, in 1966, published a paper on obstructive unilobar emphysema in neonates, ${ }^{[37]}$ and in 1967 was the lead anaesthetist in the first successful separation of craniopagus twins in SA, at the Transvaal Memorial Hospital for Children. ${ }^{[38]}$

\section{Women at the helim}

By the mid-1960s, Vetten, Ginsberg and Barlow were the principal anaesthetists at the helm of the three major teaching hospitals, serving the white, black and coloured populations of SA's largest city. Johannesburg Hospital was the academic centre, but Baragwanath, a sprawling medical complex serving the majority of the black population, had the largest anaesthetic department. In his memoir, neurosurgeon Colin Froman paints a vivid picture of surgical colleagues encountered in the anaesthetic department at Baragwanath in the 1960s: '[a] strange clique of plain women and gay men' presided over by 'the Great White Queen, Hilda [sic] Ginsberg-Wayburne, Chief Anaesthetist, illustrious teacher, great intubator, and Mistress of Her Domain', whose favour determined which surgeons were allotted anaesthetists and which 'queued and waited. ${ }^{\text {[24] }}$ Froman's cartoonish account says as much about the attitude of surgeons (and prejudice of the time) as it does about the department under Ginsberg. But it shows how much had changed since anaesthetics was an ancillary department under surgery, when surgeons seemed 'very conscious of the derivation of the word "ancillary" from the Latin ancilla, meaning "housemaid, female servant or female slave". [39]

On the same day in November 1968, all three were promoted to associate professor. Vetten might have joined Ginsberg and Barlow in being appointed head of her hospital's anaesthetic department (making her head of the university department). ${ }^{[18]}$ From 1954, she acted as deputy to the head of department. ${ }^{[18]}$ However, on applying for the post, she was told: '[w] e would like to have you, but you are too much of a lady. You really have to be a bastard to be a professor. You have really got to be nasty. And we think you are too soft.' Vetten received the outcome (the post being given to a male applicant with a less impressive record) with stoicism: 'I just carried on.' ${ }^{[25]}$ Being a 'lady' meant accepting constraints. The promotion of a woman to full professor and head of anaesthesia at Wits came only after Vetten's lifetime.

In the 1970s, Vetten participated in experimental research on liver transplantation in primates with the aim of developing a colony of chacma baboons with transplanted livers that could then be used to assess various forms of immunosuppression. Research of this kind had not previously been conducted at altitude. Requiring a safe technique to avoid hypoxia, she developed a standardised, muscle relaxant-free technique using phencyclidine and fluoroxene with oxygen (avoiding nitrous oxide), which could be administered by technicians in Johannesburg at $\sim 1800 \mathrm{~m}$ above sea level. At the time of publication of her paper, after 200 consecutive liver transplants using this technique, no subjects had died. ${ }^{[40]}$

Barlow had identified valuable samples for research into genetic malignant hyperpyrexia after deaths under anaesthesia at Coronation Hospital in 1962 and 1963, and a third in 1964, where the patients were found to be related. She consulted with a neuromuscular specialist colleague, Hyam Isaacs, and together they performed ground-breaking research on the use of creatinine phosphokinase (CPK) as a screening marker of the condition in family members, publishing important findings in $1970,^{[41,42]}$ with follow-up studies in $1973{ }^{[43,44]}$ Although CPK was later shown to be less reliable than muscle biopsy in diagnosing susceptibility to the condition, it was of critical importance in placing malignant hypothermia among the myopathies. ${ }^{[45]}$

In 1975, after a third term as SASA president and nearly 30 years of service, including 3 terms as secretary, 7 Council terms and 9 terms as secretary/treasurer, Ginsberg was made honorary life vice-president of SASA, ${ }^{[3]}$ the Society's highest honour.

\section{Conclusions}

Barlow, Vetten and Ginsberg each made major contributions to anaesthesia: Vetten in the application of animal research to medicine; Ginsberg in her extraordinary leadership; and Barlow in bringing down professional barriers to women in anaesthesia. The greatest barrier, the marriage bar, upheld that a woman's primary public service role was that of mother. All three women negotiated this dual role in the 'health of the nation', establishing families while building 
medical careers. Ginsberg does not appear in the photograph of the Society's inaugural meeting, because she was then giving birth to a second child. On the first page of Vetten's CV, in which she carefully chronicles her history of professional achievements (never enough to win her the professional recognition she sought), she listed her three sons (by name) and 'eight grandchildren. Barlow, who went into full-time hospital practice when her youngest child was 6 years old, wrote of her children in her medical biography, "both are university graduates and happily married. Neither feels I neglected them when they were children.' Noting, with some pride, that she stopped working only when she was pregnant, she insisted that she 'did a great deal of night duty' to be available for important moments in her children's lives, and that when they were small, she 'hired good night nurses. ${ }^{[7]}$

It is worth pausing, and perhaps ending, on this detail. Colonial administration and apartheid government ensured a supply of domestic labour that enormously eased the work of white South Africans. Bantu education, which so poorly equipped black South Africans for work in anaesthesia, was designed to feed this pool of unskilled labour. While Barlow, Ginsberg and Vetten helped anaesthesia rise up to become more than the handmaid to surgery, they were helped in their own homes by handmaids in a literal sense, who significantly shared the domestic burden they would otherwise have been expected to carry. The grandchildren and great grandchildren of this generation of handmaids may have opportunities to pursue careers in anaesthetics and contribute to the further development of anaesthesia in SA, although apartheid's waste of human capital will take a long time to overcome.

Declaration. None.

Acknowledgements. Dr Lisa Vetten allowed the authors access to Barbara Vetten's papers. Prof. Arthur Rantloane shared information about early black female anaesthetists.

Author contributions. The authors contributed equally to research and writing of this article.

Funding. None.

Conflicts of interest. None.

1. Hewitt FW. The past, present, and future of anaesthesia. Practitioner 1896:347-356.

2. Sacks G. Obituary: Royden Muir. S Afr Med J 1948;22(23):779.

3. Parbhoo NP. Five Decades: The South African Society of Anaesthetists 1943 - 1993. Johannesburg: South African Society of Anaesthetists, 1993.

4. The Editor. Medico-Ethical. Employment of dentist as anaesthetist. J Med Ass SA 1927;1(2):69.

5. Orenstein AJ, Robertson LS. Report of the committee on deaths under anaesthesia. S Afr Med J 1936;11:729-734.

6. Hellstedt LM. Women Physicians of the World: Autobiographies of Medical Pioneers. Washington, DC: Hemisphere, 1978.
7. Wayburne (nee Ginsberg), Hilde (1911 - 2010). In Memoriam. WITSReview 2011:58. https://www wits.ac.za/alumni/obituaries/obituary-content-by-year/\#d.en.1762326 (accessed 12 October 2020). Meaker KB. Human remains from the Hole-in-the-Wall, Mqanduli, Transkei. S Afr J Sc 1935;32:609-612

9. Digby A. Early black doctors in South Africa. J Afr Hist 2005:427-454.

10. Digby A. Black doctors and discrimination under South Africas's apartheid regime. Med Hist 2013;57(2):269-290. https://doi.org/10.1017/mdh.2012.106

1. Lapping B. Apartheid: A History. New York: Braziller, 1987

2. Tobias PV. Apartheid and medical education: The training of black doctors in South Africa. Int $J$ Health Serv 1983;13(1):131-153. https://doi.org/10.2190/FCEQ-9W7L-WD9P-5CP9

3. Walker E. The South African Society of Medical Women, 1951 - 1992: Its origins, nature and impact on white women doctors. PhD thesis. Johannesburg: University of the Witwatersrand, 1999.

14. Keene R. Our Graduates 1924 - 2012. Johannesburg: Faculty of Health Sciences (Wits), 2013.

15. Murray BK. Wits as an 'open' university, 1939 - 1959: Black admissions to the University of the Witwatersrand. J South Afr Studies 1990;16(4):649-676. https://doi.org/10.1080/03057079008708255

16. Walker L. 'Conservative pioneers': The formation of the South African Society of Medical Women Soc Hist Med 2001;14(3):483-505. https://doi.org/10.1093/shm/14.3.483

17. Robertson I. Miriam Brereton Barlow (Mollie McWilliam Smith). S Afr Med J 1990;77(5):489.

17. Robertson I. Miriam Brereton Barlow (Mollie McWilliam Smith). S Afr Med J 1990;77(5):489.
18. University of Witwatersrand. Appointments: Associate Professors. Wits Gazette 1969;(Dec):7-11.

18. University of Witwatersrand. Appointments: Associate Professors. Wits Gazette 1969,

19. Rossouw R. Call for a doctors' truth commission. Mail and Guardian, 2 August 1996.

20. Barlow MB, Ginsberg H, Gottlich J. Deaths at a non-European Hospital. S Afr Med J 1953;27(3):242-246. Sunday 9th October 1960. The Annual General Meetings of the SA Society of Anaesthetists and the History of the Society 1943 - 1968. Hist Anaesth Museum Arch 1960:129-136.

22. Gordon PC, James MF. The role of the College of Medicine of South Africa Diploma in Anaesthesia in southern Africa. S Afr Med J 1999;89(4):416-418.

23. Gordon PC, Fourie P. SASA 75 Years 1993 - 2018. Johannesburg: South African Society of Anaesthesiologists, 2018.

24. Froman C. The Barbershop Quartet. Vancouver: Trafford, 2006.

25. Walker L. Resisting constraints, creating opportunities. The experiences of some early medical women. S Afr Med J 1997;87(11):1508-1512

26. Meaker B, Jokl E. Mechanisms of athletic injuries. S Afr J Sci 1942;38:259-266.

27. Vetten KB, Nicholson JC. Muscular relaxants: A comparison of decamethonium iodide and d-tubocurarine chloride in anaesthesia. Anaesthesia 1950;5:175-186.

chloride in anaesthesia. Anaesthesia 1950;5:175-186.
28. Vetten KB, Nicholson JC, Devitt DC. Safety in the use of muscular relaxants. S Afr Med J 1952;26:814-817.

29. Crawshaw GR, Vetten KB, Wilson VH. Mitral incompetence in the dog. An experimental method. Crawshaw GR, Vetten KB, W
S Afr J Med Sci 1953;18:79-83.

30. Crawshaw GR, Wilson VH, Kreel L, Vetten KB, Borman JB. Experimental mitral incompetence in dogs: Crawshaw GR, Wilson VH, Kreel L, Vetten KB, Bo
Studies in haemodynamics. Br J Surg 1954:319-327.

1. Wilson VH, Crawshaw GR, Vetten KB. S Afr J Med Sci 1955;20:71-72

32. Vetten KB, Wilson VH, Crawshaw GR, Nicholson JC. Experimental studies in cardiac massage with special reference to aortic occlusion. Br J Anaesth 1955;27:2-13.

33. Wilson VH. Assisted circulation. S Afr Med J 1956;30(6):545-547.

34. Vetten KB, Wilson VH, Crawshaw R. Some problems of anaesthesia encountered in experimental cardiac research. S Afr J Med Sci 1956;21:1-8.

35. Vetten KB. A few problems relating to anaesthesia for cardio-pulmonary bypass procedures. S Afr Med J 1965;39(10):948-952.

36. Vetten KB. Anaesthesia for renal transplantation. A preliminary report. S Afr Med J 1970;44(4):437-444. https://doi.org/10.1093/bja/45.1.10

37. Vetten KB. Air trapping in the lungs of neonates: Obstructive unilobar emphysema in neonates. Vetten KB. Air trapping in
Med Proceed 1966;12(1):3-6

38. Wolfowitz FKE, Levin DH, Walker DH, Vetten KB. Separation of craniopagus twins. S Afr Med Wolfowitz FKE, Le

1968:42(4):412-424.
39. Louw JH. In the Shadow of Table Mountain A History of the University of Cape Town Medical School. Cape Town: Struik, 1969.

0. Vetten KB, Myburgh JA, Mieny CJ, Bersohn I, Isaacs F, Nermudzhivadi A. Anaesthesia for live transplantation in primates. Br J Anaesth 1973;45(1):10-20.

1. Isaacs H, Barlow MB. Malignant hyperpyrexia during anaesthesia: Possible association with subclinica myopathy. Br Med J 1970;1(5691):275-277. https://doi.org/10.1136/bmj.1.5691.275

42. Barlow MB, Isaacs $\mathrm{H}$. Malignant hyperpyrexial deaths in a family. Reports of three cases. Br J Anaesth 1970;42(12):1072-1076. https://doi.org/10.1093/bja/42.12.1072

43. Isaacs $\mathrm{H}$, Barlow $\mathrm{MB}$. The genetic background to malignant hyperpyrexia revealed by serum creatine phosphokinase estimations in asymptomatic relatives. Br J Anaesth 1970;42(12):1077-1084. https://doi. phosphokinase estimation in

44. Isaacs H, Barlow M. Malignant hyperpyrexia occurring in a second Johannesburg family. Br I Anaesth 1973;45:901-906.

45. Harriman DG. Malignant hyperthermia myopathy - a critical review. Br J Anaesth 1988;60:309-316.

Accepted 14 January 2020. 